\title{
Relational coordination between professionals predicts satisfaction with home visit nursing care
}

\author{
Mahiro Sakai *, Takashi Naruse, Satoko Nagata \\ Department of Community Health Nursing, Division of Health Sciences and Nursing, Graduate School of Medicine, The \\ University of Tokyo, Tokyo, Japan
}

Received: September 15, 2015

Accepted: October 11, 2015

Online Published: October 26, 2015

DOI: $10.5430 / \mathrm{cns} . v 4 \mathrm{n} 1 \mathrm{p} 1$

URL: http://dx.doi.org/10.5430/cns.v4n1p1

\begin{abstract}
The authors aimed to identify the relationship between relational coordination among home visit nurses and other home healthcare workers and nursing care satisfaction. In November 2013, the authors collected data from 190 nurses in 34 of 64 home visit nursing agencies in Miyazaki prefecture, Japan. Data were returned by 119 individuals through a web-based or mail survey. Nursing care satisfaction among their clients during the most recent 6 months was evaluated by primary nurses (possible scores: 0-10), based on which the authors created a low-satisfaction (Low-SG) and a high-satisfaction (High-SG) group. Nurses' relational coordination with nursing colleagues, nursing managers, clinicians, care managers, and home helpers was measured with the Relational Coordination Scale Japanese version (Relational Coordination Scale Japanese version [RCS-J]; possible scores: 1-5). Multivariate logistic regression analysis was used to analyze the data. Using data from 90 nurses because of missing data, the RCS-J scores were 3.5 (standard deviation $[\mathrm{SD}]=0.6$ ) and $3.8(\mathrm{SD}=0.5)$ for Low-SG and High-SG groups, respectively. Multivariate logistic regression analysis showed that RCS-J scores were positively associated with nursing care satisfaction (odds ratio $[\mathrm{OR}]=3.05,95 \%$ confidence interval: $1.25-7.45$ ). Further, nurse's age was positively associated with nursing care satisfaction $(\mathrm{OR}=1.10,95 \%$ confidence interval $[\mathrm{CI}]: 1.02-1.18)$. This finding suggests that well-coordinated home healthcare teams provide higher quality of care than do poor-coordinated teams. However, the results depended on nurses' self-reports. Future research using a more objective index of quality of care would contribute to understanding the benefits of relational coordination.
\end{abstract}

Key Words: Care satisfaction, Cross-sectional survey, Home care, Home visit nursing, Relational coordination, Teamwork

\section{INTRODUCTION}

Home visit nursing recipients receive, on average, one or more medical services and more than four kinds of long-term care services in Japan. ${ }^{[1]}$ Generally, provision of nursing care requires teamwork based on coordination among healthcare professionals to properly address the comprehensive needs of care recipients. ${ }^{[2]}$ In particular, a previous study reported that coordination among professionals enhances integrated care delivery to hospitalized older patients. ${ }^{[3]}$ In a home care setting, the work of home healthcare profes- sionals is interdependent and time constrained. Accordingly, a well-coordinated relationship between nurses and other professions is needed to ensure better nursing care.

Home visit nursing care recipients often take a sudden turn for the worse, and they tend to be in a precarious state of health. Accordingly, home visiting nurses must assess and present the medical status of care recipients to other professionals involved. Nurses' roles here are similar to those in their core area of expertise reported in health and social care for older people. ${ }^{[4]}$ By taking advantage of other profession-

\footnotetext{
*Correspondence: Mahiro Sakai; Email: sfmahiro-tky@umin.ac.jp; Address: Department of Community Health Nursing, Division of Health Sciences and Nursing, Graduate School of Medicine, The University of Tokyo, 7-3-1, Hongo, Bunkyo-ku, Tokyo, 113-0033, Japan.
} 
als' care and attention to medical status, nurses might be able to better encourage clients' recuperation at home and meet clients' expectations. That is, promoting teamwork would enrich care recipients' quality of life.

To the best of our knowledge, there are four types of teamwork in healthcare and social care professions. According to Reeves ${ }^{[2]}$ typology of teamwork, there are networking, coordination, collaboration, and narrowly defined teamwork types. Among these, coordination encompasses casemanagerial aspects of teamwork. Gittell ${ }^{[5]}$ insisted that relational coordination is particularly important for the achievement of desired outcomes in settings that involve high levels of task interdependence, uncertainty, and time constraints, which are similar conditions to those that exist in home care settings. Relational coordination is defined as a "mutually reinforcing process of interaction between communication and relationships carried out for the purpose of task integration" ${ }^{[5]}$ According to the theory of relational coordination, ${ }^{[6]}$ high-quality communication (frequent, timely, accurate, and problem-solving) reinforced by high-quality relationships with clients (shared goals, shared knowledge, and mutual respect) enable nurses to effectively coordinate work, which has positive implications for quality, efficiency, and workforce satisfaction. The coordination level of team members can be measured with Gittell's Relational Coordination Scale. ${ }^{[7]}$

Effects of relational coordination have been examined in hospital settings and in nursing home settings. For example, relational coordination among nursing staff in hospitals has a positive impact on patient satisfaction. ${ }^{[8]}$ Nurses' and nursing aids' relational coordination might enhance the quality of life among nursing home residents. ${ }^{[9]}$ However, the effects of relational coordination have not been identified, especially in home care settings.

Previous studies have theoretically and practically demonstrated that relational coordination is associated with patient outcomes. ${ }^{[9,10]}$ For patient outcomes, nursing care satisfaction is enriched by nurses' caring behaviors. ${ }^{[11]}$ Though caring behavior is a wide-ranging concept,$^{[12]}$ the nature of this concept includes attentive listening to patients and coordinating resources for responding to patients' comprehensive needs. ${ }^{[13]}$ If nurses are well-coordinated with other professions, which are resources for responding to care recipients' needs, care recipients will be more satisfied with nursing care In addition, care satisfaction has generally been measured as a patient outcome that is related to the care provided. ${ }^{[14]}$

Accordingly, the authors first focused on nursing care satisfaction as a patient outcome. The authors aimed to identify the relationship between relational coordination among home visiting nurses and other home healthcare workers and nursing care satisfaction.

\section{Materials AND Methodology}

\subsection{Design and setting}

This cross-sectional study employed a web-based and mail survey in Miyazaki prefecture in the Kyushu district of western Japan in November 2013. The study was approved by the ethics committee of The University of Tokyo. The authors obtained written consent for participation from each nursing manager. Consent from participants other than nursing managers was considered as given when the questionnaire was answered or returned to the authors. Participants were informed in writing about their freedom to participate, refuse to participate, and withdraw from participation, as well as about the anonymity of the questionnaire, protection of participant privacy, and our intent to publish the study results.

\subsection{Participants}

Among all 64 home visit nursing agencies placed in Miyazaki, 190 nurses working in 34 agencies participated, and data were returned by 119 individuals through the webbased or mail survey.

\subsection{Measurements}

Participant characteristics measured were sex, age, years of home visit nursing, years at current workplace, employment status, and number of visits per day. Relational coordination was measured with the Relational Coordination Scale Japanese version (RCS-J). ${ }^{[15]}$ Nurses' relational coordination with nursing colleagues, nursing managers, clinicians, care managers, and home-helpers during the most recent 6 months were assessed in terms of three relationship aspects (i.e., shared goals, shared knowledge, and mutual respect) and communication aspects (i.e., frequency, timeliness, accuracy, and problem-solving) for each profession. The RCS-J score was obtained by calculating the arithmetic mean of all professions with a possible range from 1 to 5. Cronbach's $\alpha$ in this study for each profession was $.878, .876, .898, .887$, and .903 for nursing colleagues, nursing managers, clinicians, care managers, and home-helpers, respectively. Cronbach's $\alpha$ for the RCS-J of this study was .857.

Nursing care satisfaction reflected general nursing care satisfaction among clients (as evaluated by primary nurses) over the most recent 6 months. The authors originally developed this rating scale to measure quality of care on a 0-10 scale. In the analysis, the authors divided scores into a low-satisfaction group (Low-SG) and a high-satisfaction group (High-SG) based on the distribution of the data shown in Figure 1. 


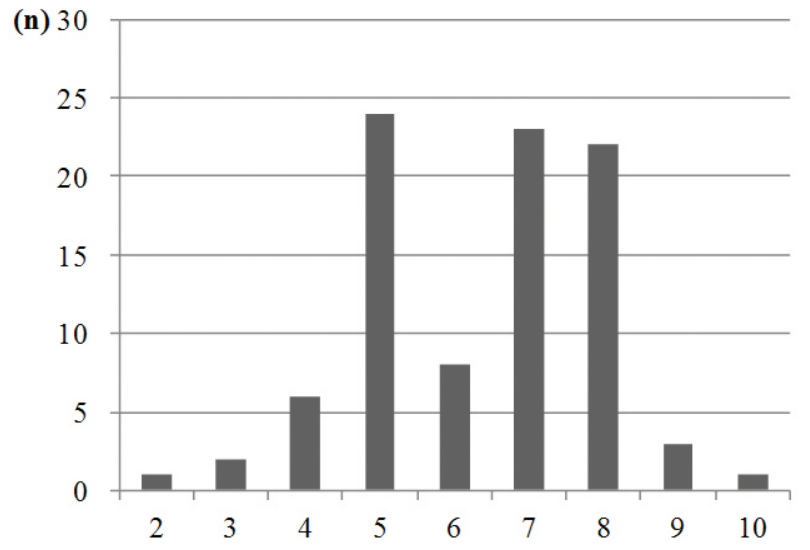

Figure 1. Nursing care satisfaction

\subsection{Statistical analysis}

The authors used descriptive statistics to describe participant characteristics, RCS-J scores, and nursing care satisfaction. The authors used mean (standard deviation [SD]) to represent continuous variables and $n(\%)$ for categorical variables. The authors then conducted bivariate logistic regression analysis. In this stage, selected variables were entered into multivariate regression analysis. Among variables, there was a Pearson correlation of .631 between years of home visit nursing and years at current workplace, and so years of home visit nursing was selected for the analyses. Finally, multivariate logistic regression analysis was conducted to identify the relationship between relational coordination among home visiting nurses and other home healthcare workers and nursing care satisfaction.

\section{RESULTS}

Questionnaires were returned by 119 participants by mail or through the web survey. The authors excluded data from 26 who were nursing managers, as they usually did not conduct home visits, two nurses who did not answer items of the RCS-J, and one nurse who did not complete the nursing care satisfaction item. In total, data of 90 nurses were analyzed.

Participant characteristics and the results of bivariate logistic regression analysis are shown in Table 1. Most participants were female (97.8\%). Mean (SD) age, years of home visit nursing, and years at current workplace were $42.9(\mathrm{SD}=7.6)$, $6.2(\mathrm{SD}=5.6)$, and $4.3(\mathrm{SD}=4.1)$, respectively. Sixty-two nurses were full-time workers $(68.9 \%)$, and the mean number of home visits per day was 3.7 ( $\mathrm{SD}=1.1$, range $=1.0-6.0)$. The mean overall RCS-J score was $3.7(\mathrm{SD}=0.6$, range $=$ 1.0-4.9), and the mean general satisfaction score was 6.4 (SD $=1.6$, range $=2.0-10.0)$. The RCS-J scores were $3.5(\mathrm{SD}=$ $0.6)$ and $3.8(\mathrm{SD}=0.5)$ for Low- and High-SG, respectively. Variables associated with nursing care satisfaction were age (crude odds ratio $[\mathrm{OR}]=1.200,95 \%$ confidence interval $[\mathrm{CI}]$ : 1.028-1.169) and relational coordination (crude $\mathrm{OR}=2.856$, 95\% CI: $1.212-6.733)$.

Results of the multivariate logistic regression analysis are shown in Table 2. Relational coordination was positively associated with nursing care satisfaction $(\mathrm{OR}=3.05,95 \% \mathrm{CI}$ : 1.25-7.45) in adjusting for age, years of working as a home visiting nurse, and number of home visits per day. Further, age was positively associated with nursing care satisfaction $(\mathrm{OR}=1.10,95 \%$ CI: $1.02-1.18)$.

Table 1. Participant characteristics and bivariate logistic regression results $(\mathrm{N}=90)$

\begin{tabular}{|c|c|c|c|c|c|c|}
\hline \multirow{2}{*}{ Variables } & \multirow{2}{*}{$\begin{array}{l}\text { N }(\%) \\
\text { Mean } \pm \text { SD (Min-Max) }\end{array}$} & \multirow{2}{*}{ Low-SG $n=41$} & \multirow{2}{*}{ High-SG $n=49$} & \multicolumn{3}{|c|}{ Nursing care satisfaction } \\
\hline & & & & Crude OR & $95 \% \mathrm{CI}$ & $p$-value \\
\hline Sex & & & & & $(0.073-19.801)$ & .899 \\
\hline Female & $88(97.8)$ & $40(97.6)$ & $48(98.0)$ & 1.200 & & \\
\hline Male & $2(2.2)$ & $1(2.4)$ & $1(2.0)$ & 1 & & \\
\hline Age & $42.9 \pm 7.6(27.0-63.0)$ & $40.4 \pm 6.9(27.0-63.0)$ & $45.0 \pm 7.5(33.0-63.0)$ & 1.096 & $(1.028-1.169)$ & .005 \\
\hline Years as home visit nursing & $42.9 \pm 7.6(27.0-63.0)$ & $5.3 \pm 4.8(0.0-15.0)$ & $6.7 \pm 6.1(1.0-31.0)$ & 1.051 & $(0.970-1.139)$ & .222 \\
\hline Years at curent workplace & $4.3 \pm 4.1(0.0-19.0)$ & $3.7 \pm 3.9(0.0-15.0)$ & $4.7 \pm 4.2(1.0-19.0)$ & 1.060 & $(0.953-1.180)$ & .282 \\
\hline Employment status & & & & & $(0.347-2.098)$ & .730 \\
\hline Full-time & $62(68.9)$ & $29(70.7)$ & $33(67.3)$ & 0.853 & & \\
\hline Part-time & $28(31.1)$ & $12(29.3)$ & $16(32.7)$ & 1 & & \\
\hline Number of visits per day & $3.7 \pm 1.1(1.0-6.0)$ & $3.8 \pm 1.1(2.0-6.0)$ & $3.6 \pm 1.1(1.0-6.0)$ & 0.862 & $(0.585-1.270)$ & .452 \\
\hline Relational coordination & $3.7 \pm 0.6(1.0-4.9)$ & $3.5 \pm 0.6(1.0-4.3)$ & $3.8 \pm 0.5(2.7-4.9)$ & 2.856 & $(1.212-6.733)$ & .016 \\
\hline Nursing care satisfaction & $6.4 \pm 1.6(2.0-10.0)$ & $4.9 \pm 0.9(2.0-6.0)$ & $7.6 \pm 0.7(7.0-10.0)$ & & & \\
\hline
\end{tabular}

Note. Missing data not included; Abbreviation: SG = Satisfaction group

\section{Discussion}

There was a positive relationship between relational coordination with home healthcare professions and nursing care satisfaction as assessed by home visiting nurses. Nurse's age was also positively associated with nursing care satisfaction. These findings support our hypothesis regarding the relationship between relational coordination and nursing care satisfaction. 
As mentioned previously, caring behaviors and relational coordination are related to patient satisfaction in other care settings,${ }^{[8,16]}$ and thus, the finding of this study is supported by those of the previous studies. In a home care setting, given the short nature of visits, home visiting nurses have less time to directly assess and respond to clients' needs than do nurses working in hospitals or institutional care facilities. Accordingly, home visiting nurses must utilize case-managerial teamwork and relational coordination with other professions to facilitate adequate caring behaviors. Prior to their home visits, collecting information regarding clients' conditions and needs from other professionals and asking them to make recommendations on how to fulfill clients' needs is necessary, as nurses cannot complete all of these duties during short home visits. This will allow team members to react instantly to clients' needs, which might explain why High-SG nurses had higher RCS-J scores than did Low-SG nurses.

Table 2. Multivariate logistic regression analysis $(\mathrm{N}=90)$

\begin{tabular}{llll}
\hline Variables & Odds ratio & $\mathbf{9 5 \%}$ confidence interval & $\boldsymbol{p}$-value \\
\hline Age & 1.10 & $(1.02-1.18)$ & .009 \\
Years as home visiting nurse & 1.03 & $(0.94-1.12)$ & .570 \\
Number of visits per day & .78 & $(0.50-1.22)$ & .284 \\
Relational coordination & 3.05 & $(1.25-7.45)$ & .014 \\
\hline
\end{tabular}

Note. Nursing care satisfaction: $0=$ Low satisfaction, $1=$ High satisfaction; CoxSnell $\mathrm{R}^{2}=.175$, Nagelkerke $\mathrm{R}^{2}=.233 ;$ Hosmer $\&$ Lemeshow test $\chi^{2}=6.675, p=.572$

It was found that older nurses had higher client satisfaction scores than did younger nurses. However, the number of years of experience as a home visit nurse was not associated with nursing care satisfaction. This result might be explained by the following two findings from previous studies in the general population. First, adults develop improved emotional regulation over the lifespan. ${ }^{[17,18]}$ Second, older adults assess their actions more positively by maximizing positive affect and minimizing negative affect as compared to younger adults. ${ }^{[18,19]}$ According to Carstensen's socioemotional selectivity theory, the role of affect becomes more prominent with age, but emotion regulation simultaneously improves with age. ${ }^{[18]}$ Gross et al. ${ }^{[20]}$ demonstrated that older adults report slightly higher levels of positive affect than do younger adults. Emotion regulation changes in later life lead to higher positive affect and lower negative affect. Another study found an increase in positive affect with age among women. ${ }^{[21]}$ In the present study, given that most participants were women, it might have been detected an effect of age on positive evaluations of nursing care satisfaction. Thus, it is possible that, for these reasons, older nurses assessed their nursing care more positively than did younger nurses.

\section{Implications for practice and future research}

Interestingly, in adjusting home visit nursing experience and number of visits, a positive relationship between relational coordination and care satisfaction was identified. That is, even those with less experience in home care and home visits might provide better nursing care as a function of relational and coordinative support from team members. In a rapidly aging society, home visiting nurses have difficulty visiting other professionals' agencies, communicating face-to-face, and developing relationships with them, as approximately $30 \%$ of nurses face time pressures in home care and trips to clients' homes. ${ }^{[22]}$ Further, distance between nursing agencies and those of other professions is often a barrier to communication. Work-related exhaustion was found to be the strongest inverse predictor of work satisfaction in elderly care. ${ }^{[23]} \mathrm{A}$ poorly coordinated team can exhaust nurses, thereby hindering their ability to provide direct care for clients. Gittell ${ }^{[6]}$ reported that work environment systems could improve relational coordination in staffs' tasks. Thus, nursing managers' support for staff nurses in assessing and developing relational coordination with other professions should decrease work stress and promote better home visit nursing care.

This study has several limitations. First, this study was conducted in one prefecture of Japan. There are some differences in the distribution of agencies providing home healthcare services as compared to other regions of Japan. This might limit the generalizability of the results. Second, for some of the nurses who participated in this study, social operant mechanisms may have implicitly resulted in greater satisfaction with nursing care as a function of better coordination with some professionals. The inability to exclude the possibility of this potential mechanism was a limitation of the study design. Future research is needed to observe the relationship between these variables prospectively. Third, the authors did not examine the other professionals' assessments about their relational coordination and care satisfaction. If these variables were included, different results might have been obtained. In addition, it could not be examined how relational coordination might affect nursing care satisfaction as a func- 
tion of client and team characteristics. Future studies should examine in more detail whether the ability of relational coordination to predict care satisfaction, as found in this study, can be applied to other countries and data obtained from other professions. Furthermore, the authors should examine whether the relationship holds in considering the effects of characteristics of clients and teams.

\section{Conclusion}

This study found that relational coordination among home healthcare professionals and age were significantly associated with nursing care satisfaction as assessed by home visiting nurses. This finding suggests that well-coordinated home healthcare teams provide higher quality of care as compared to poorly coordinated teams. However, the results depended on nurses' self-reports. Future research on a more objective index of quality of care would contribute to the investigation of the benefits of relational coordination. Additionally, future research should explore whether relational coordination patterns vary by client and team characteristics.

\section{ACKNOWLEDGEMENTS}

The authors would like to thank all the participants.

\section{CONFLicts OF INTEREST Disclosure}

The authors report no conflict of interest.

\section{REFERENCES}

[1] Igarashi A, Ishibashi T, Shinozaki T, et al. Combinations of long-term care insurance services and associated factors in Japan: a classification tree model. BMC Health Serv Res. 2014; 14: 382.

[2] Reeves S, Lewin S, Espin S, et al. Interprofessional teamwork: key concepts and issues. Interprofessional teamwork for health and social care. Chichester, West Sussex: Blackwell Pub; 2010. 39-56 p. http://dx.doi.org/10.1002/9781444325027.ch3

[3] Hartgerink JM, Cramm JM, Bakker TJ, et al. The importance of relational coordination for integrated care delivery to older patients in the hospital. Journal of nursing management. 2014; 22(2): 248-56. PMID:24576117. http://dx.doi .org/10.1111/j.1365-2834. $2012.01481 . \mathrm{x}$

[4] Baxter SK, Brumfitt, Shelagh M. Professional differences in interprofessional working. Journal of Interprofessional Care. 2008; 22(3): 239-51. PMID:18569411. http://dx.doi.org/10.1080/13561 820802054655

[5] Gittell JH. Organizing work to support relational co-ordination. Int J Hum Resour Manag. 2000; 11(3): 517-39. http://dx .doi.org/1 $0.1080 / 095851900339747$

[6] Gittell JH. New Directions for Relational Coordination Theory. The Oxford Handbook of Positive Organizational Scholarship 2011. 400$11 \mathrm{p}$.

[7] Gittell JH, Weinberg DB, Bennett A, et al. A relational approach to job design and the coordination of work. Heller School Working Paper, Brandeis University; 2007.

[8] Bae SH, Mark B, Fried B. Impact of nursing unit turnover on patient outcomes in hospitals. Journal of nursing scholarship. 2010; 42(1): 40-9. PMID:20487185. http://dx.doi.org/10.1111/j $.1547-5069.2009 .01319 . x$

[9] Gittell J Hoffer, Weinberg Dana, Pfefferle Susan, et al. Impact of relational coordination on job satisfaction and quality outcomes: a study of nursing homes. Human Resource Management Journal. 2008; 18(2): 154-70. http://dx.doi.org/10.1111/j.1748-8 $583.2007 .00063 . x$

[10] Van Houdt S, Heyrman Jan, Vanhaecht Kris, et al. An in-depth analysis of theoretical frameworks for the study of care coordination. International Journal of Integrated Care. 2013; 13(e024). PMID:23882171.

[11] Rafii F Hajinezhad, Mohammad Esmaiel, Haghani Hamid. Nurse caring in Iran and its relationship with patient satisfaction. Australian Journal of Advanced Nursing. 2008; 26(2): 75-84.

Published by Sciedu Press
[12] Boykin A, Schoenhofer S. Nursing as caring: a model of transforming practice. Boston, Massachusetts, USA.: Jones and Bartiett; 2001.

[13] Wolf ZR, Giardino RE, Osborne AP, et al. Dimensions of Nurse Caring. Jounarl of Nursing Scholarship. 1994; 26(2): 107-12. http: //dx.doi.org/10.1111/j.1547-5069.1994.tb00927.x

[14] Geron SM, Smith K, Tennstedt S, et al. The home care satisfaction measure: a client-centered approach to assessing the satisfaction of frail older adults with home care services. The journals of gerontology Series B, Psychological sciences and social sciences. 2000; 55(5): S259-70. PMID:10985297. http://dx.doi.org/10.1093 /geronb/55.5.S259

[15] Naruse T, Sakai M, Nagata S. Reliability and validity of the Japanese version of the Relational Coordination Scale. Japanese journal of public health. 2014; 61(9): 565-73. PMID:25298090.

[16] Wolf ZR, Colahan M, Costello A. Relationship between nurse caring and patient satisfaction. 1998; 7(2): 99-105.

[17] Labouvie-Viefa G, Blanchard-Fields Fredda. Cognitive Ageing and Psychological Growth. Ageing and Society. 1982; 2(2): 183-209. http://dx.doi.org/10.1017/S0144686X00009429

[18] Carstensen LL. Evidence for a Life-Span Theory of Socioemotional Selectivity. Current Directions in Psychological Science. 1995; 4(5): 151-6. http://dx.doi.org/10.1111/1467-8721.ep11 512261

[19] Lawton MP. Quality of life and affect in later life. Handbook of emotion, adult development and aging. San Diego, CA: Academic Press; 1996.

[20] Gross JJ Carstensen, Laura L, Pasupathi Monisha, et al. Emotion and aging: Experience, expression, and control. Psychology and Aging. 1997; 12(4): 590-9. PMID:9416628. http://dx.doi.org/10.10 37/0882-7974.12.4.590

[21] Mroczek K Daniel, Kolarz M Christian. The effect of age on positive and negative affect: a developmental perspective on happiness. Journal of Personaloty and Social Psychology. 1998; 75(5): 1333-49. http://dx.doi.org/10.1037/0022-3514.75.5.1333

[22] Naruse T, Taguchi A, Kuwahara Y, et al. Relationship between perceived time pressure during visits and burnout among home visiting nurses in Japan. Japan Journal od Nursing Sciences. 2012; 9(2): 185194. PMID:23181887. http://dx.doi .org/10.1111/j.1742-7 924.2011.00201.x

[23] Hasson H, Arnetz JE. Nursing staff competence, work strain, stress and satisfaction in elderly care: a comparison of home-based care and nursing homes. Journal of Clinical Nursing. 2008; 17(4): 468-81. PMID: 17331093. 